\title{
Preservation of the Immunogenicity of Dry-powder Influenza H5N1 Whole Inactivated Virus Vaccine at Elevated Storage Temperatures
}

\author{
Felix Geeraedts, ${ }^{1}$ Vinay Saluja, ${ }^{2}$ Wouter ter Veer, ${ }^{1}$ Jean-Pierre Amorij, ${ }^{2,3}$ Henderik W. Frijlink, ${ }^{2}$ Jan Wilschut, ${ }^{1}$ \\ Wouter L. J. Hinrichs, ${ }^{2,4}$ and Anke Huckriede ${ }^{1}$
}

Received 30 November 2009; accepted 1 February 2010; published online 2 March 2010

\begin{abstract}
Stockpiling of pre-pandemic influenza vaccines guarantees immediate vaccine availability to counteract an emerging pandemic. Generally, influenza vaccines need to be stored and handled refrigerated to prevent thermal degradation of the antigenic component. Requirement of a cold-chain, however, complicates stockpiling and the logistics of vaccine distribution. We, therefore, investigated the effect of elevated storage temperatures on the immunogenicity of a pre-pandemic influenza A H5N1 whole inactivated virus vaccine. Either suspended in liquid or kept as a freeze-dried powder, vaccines could be stored for 1 year at ambient temperature $\left(20^{\circ} \mathrm{C}\right)$ with minimal loss of immunogenicity in mice. Elevation of the storage temperature to $40^{\circ} \mathrm{C}$, however, resulted in a significant loss of immunogenic potency within 3 months if vaccines were stored in liquid suspension. In sharp contrast, freeze-dried powder formulations were stable at $40^{\circ} \mathrm{C}$ for at least 3 months. The presence of inulin or trehalose sugar excipients during freeze-drying of the vaccine proved to be critical to maintain its immunogenic potency during storage, and to preserve the characteristic Th1-type response to whole inactivated virus vaccine. These results indicate that whole inactivated virus vaccines may be stored and handled at room temperature in moderate climate zones for over a year with minimal decline and, if converted to drypowder, even in hot climate zones for at least 3 months. The increased stability of dry-powder vaccine at $40^{\circ} \mathrm{C}$ may also point to an extended shelf-life when stored at $4^{\circ} \mathrm{C}$. Use of the more stable dry-powder formulation could simplify stockpiling and thereby facilitating successful pandemic intervention.
\end{abstract}

KEY WORDS: freeze-drying; inulin; pandemic influenza; vaccine stockpiling; whole inactivated influenza vaccine (H5N1).

\section{INTRODUCTION}

Animal influenza A viruses that cross the species barrier to humans pose a potential pandemic threat (1). Generally, these virus subtypes are antigenically different from the circulating human viruses and thus may spread rapidly in the immunologically naïve population, if human-to-human transmission is sustained. Recently, a novel H1N1 influenza virus of combined swine, avian, and human origin became pandemic within 2 months after its emergence in humans in April 2009 (2,3). In terms of virulence, this virus is comparable to the $\mathrm{H} 2 \mathrm{~N} 2$ virus that caused the relatively mild

Felix Geeraedts and Vinay Saluja contributed equally to this paper.

${ }^{1}$ Department of Medical Microbiology, Molecular Virology Section, University Medical Center Groningen and University of Groningen, Groningen, The Netherlands.

${ }^{2}$ Department of Pharmaceutical Technology and Biopharmacy, University of Groningen, Groningen, The Netherlands.

${ }^{3}$ Research and Development Unit, The Netherlands Vaccine Institute, Bilthoven, The Netherlands.

${ }^{4}$ To whom correspondence should be addressed. (e-mail: w.l.j. hinrichs@rug.nl) pandemic of 1957 (4-7). However, a similar pandemic scenario with a more virulent virus subtype like the highly pathogenic avian influenza (HPAI) H5N1 virus would be potentially catastrophic $(8,9)$. With a lethality rate of approximately $60 \%$ in reported laboratory-confirmed human H5N1 cases (10), maximum preparedness is warranted in case sustained human-to-human transmission were to evolve.

Vaccines and antivirals are critical assets in intervention strategies against pandemic influenza $(11,12)$. They represent the only countermeasures that are clearly efficacious in preventing infection and treating illness (13) and their availability plays a central role in pandemic preparedness planning. Prophylactic use of antivirals could provide shortterm protection and may be helpful for early containment of an emerging pandemic $(14,15)$. However, the control of infection in a pandemic will ultimately depend on protection provided by vaccination.

For the H5N1 virus, effective pre-pandemic vaccines have recently been developed, including whole inactivated virus (WIV) vaccine and split-virus vaccine combined with the oil-in-water emulsion adjuvants AS-03 or MF59 (16-19). Because the eventual pandemic virus may be an antigenic drift variant of the strain used to produce such pre-pandemic vaccines, a complete match with the pandemic strain cannot be guaranteed. However, the above vaccines have been 
shown to induce substantial cross-reactive immune responses to viruses of different H5N1 clades (16-18,20-23). Moreover, even at suboptimal efficacy, pre-pandemic vaccines may reduce attack rates if deployed in an early stage of the pandemic $(24,25)$ or may serve as priming dose for the true pandemic vaccine, thus saving time and resources (26). Stockpiling of pre-pandemic H5N1 vaccines is therefore considered an effective tool for containment and mitigation of an emerging pandemic (15), and stockpiles have already been established by multiple countries (27).

Current inactivated influenza vaccine formulations need to be stored refrigerated because the major antigenic component, the viral hemagglutinin (HA), is prone to degradation at higher temperatures (28). However, cold-chain requirements may seriously complicate the logistics of storage and deployment of pre-pandemic and pandemic vaccines, with a risk of vaccines escaping refrigeration. In general, cold-chain failure and thermal instability is a major cause of vaccine loss in developing countries (29), and has been linked to serious disease outbreaks (30). Development of temperature-stable vaccines for pandemic use would promote worldwide usability by diminishing the complexity of refrigerated storage and distribution logistics.

A well-known strategy to improve stability is conversion of the liquid vaccine into dry powder (31). Biopharmaceuticals like influenza vaccines are preferably desiccated using freeze-drying techniques (32). The vaccine is rapidly frozen and water is, subsequently, extracted by sublimation under reduced pressure. Detrimental stresses acting on the HA antigenic components as a result of the freeze-dry process, as well as degradation of the HA during subsequent storage, can be counteracted by the use of cryoprotectants such as specific sugars $(33,34)$. Sugar is mixed with the liquid vaccine, and during rapid freezing a glassy sugar matrix is formed in which water and vaccine constituents are captured. The physical barrier separating the vaccine constituents and molecular immobility provided by the matrix prevent the vaccine from degradation. Also, the matrix prevents further crystallization of water molecules upon extended cooling. After drying, the vaccine components are incorporated in a dry sugar glass, in which the water has been spatially replaced by sugar and the structural integrity of the vaccine constituents is preserved.

Here, we investigated the effect of ambient and high storage temperatures over time on the immunogenicity of influenza A/Vietnam/1203/2004 (H5N1) WIV vaccine. Vaccines were either stored conventionally in buffer solution or as sugarstabilized dry-powder formulations and immunogenicity was assessed in a mouse model. Inulin and trehalose sugars, which have the intrinsic capacity to maintain a glassy state at high temperatures $(35,36)$, were used as stabilizing agents.

\section{METHODS}

\section{Vaccine Preparation and Storage Conditions}

H5N1 virus (NIBRG-14) was provided by the National Institute for Biological Standards and Controls (NIBSC, Potters Bar, UK), and is a 2:6 reassortant between A/Vietnam/1194/ 2004 (H5N1) and A/PR/8/34 (H1N1) virus produced by reverse genetics technology. WIV was obtained by virus propagation on embryonated chicken eggs, and inactivation of the virus preparation with $0.1 \% \quad \beta$-propiolactone. The hemagglutinin protein concentration in the vaccines was determined by single radial immunodiffusion (SRID) (37).

Freeze-drying of WIV was performed as described previously (38). Briefly, glass vials containing a mixture of $200 \mu \mathrm{l}$ of a $16 \% \mathrm{w} / \mathrm{v}$ sugar (either trehalose or inulin) solution in HBS (2 mM Hepes, $0.15 \mathrm{M} \mathrm{NaCl}, \mathrm{pH} 7.4$ ), or HBS without sugar, and $200 \mu \mathrm{l} \mathrm{WIV} \mathrm{(66} \mu \mathrm{g}$ HA) in HBS (approximated sugar:HA ratio of 500:1 $(w / w)$ were frozen in liquid nitrogen for $10 \mathrm{~min}$ and subsequently lyophilized in a Christ Alpha 1-4 freeze-dryer (Salm en Kipp, Breukelen, The Netherlands). The setting of the freeze-dryer was $-35^{\circ} \mathrm{C}$ for the shelf temperature, $-55^{\circ} \mathrm{C}$ for the condenser temperature, and 0.220 mbar pressure. After $24 \mathrm{~h}$, the pressure was reduced to $0.060 \mathrm{mbar}$ and the shelf temperature was gradually raised to $20^{\circ} \mathrm{C}$. This status was maintained for another $24 \mathrm{~h}$. The dried samples were either directly rehydrated for experiments or stored in a silica gel containing desiccator at $20^{\circ} \mathrm{C}$ or $40^{\circ} \mathrm{C}$. The humidity in the desiccator was maintained at the level of $10 \pm$ $2 \% \mathrm{RH}$. As shown by Hinrichs et al. at $10 \% \mathrm{RH}$, trehalose and inulin glasses are equally hygroscopic (39). After, storage vaccines were rehydrated shortly before immunization.

\section{Hemagglutination of Erythrocytes}

To determine the particle titer of the vaccines a standard hemagglutination assay was used. Vaccines were serially diluted twofold in PBS in duplicate, starting with a 10 times dilution in the first well of a microtiter plate, so that the end volume per well was $50 \mu \mathrm{l}$. An equal volume of a $1 \%$ suspension of fresh guinea pig erythrocytes in PBS was added and the plates were incubated at room temperature for $2 \mathrm{~h}$. The titer was determined as the reciprocal of the highest dilution that yielded complete hemagglutination.

\section{Hemolysis of Erythrocytes}

The hemolysis assay was performed as described previously (40). In short, WIV vaccine (1 $\mu \mathrm{g} \mathrm{HA})$ in $50 \mu \mathrm{l} \mathrm{HNE}$ buffer (5 mM Hepes, $0.15 \mathrm{M} \mathrm{NaCl}, 0.1 \mathrm{mM}$ EDTA, pH 7.4) was added to $4 \times 10^{7}$ human erythrocytes in $800 \mu \mathrm{HNE}$. Fifty microliters of fusion buffer ( $\mathrm{pH} 5.5$ ) was added to initiate viral membrane fusion. The total mixture was incubated $0.5 \mathrm{~h}$ at $37^{\circ} \mathrm{C}$, and subsequently centrifuged at $350 \times \mathrm{g}$ for $10 \mathrm{~min}$. Absorbance of the supernatant was red at $540 \mathrm{~nm}$, representing the hemoglobin liberated from the lysed erythrocytes. The absorbance was corrected for autohemolysis in absence of WIV vaccine. The amount of hemolysis was then given as a percentage of the maximal hemolysis, which was determined by lysing erythrocytes in water.

\section{Immunization}

For immunization experiments, 8-10-week-old female Balb/c mice were purchased from Harlan Netherlands B.V. (Zeist, The Netherlands). All experiments were conducted with approval of the local Institutional Animal Care and Use Committee. Mice were intramuscularly injected in both their calf muscles with a total of $50 \mu \mathrm{l}$ WIV vaccine $(5 \mu \mathrm{g} \mathrm{HA})$ in HBS, equally divided over both injection sites. Mouse numbers per immunization group were as follows: liquid WIV; $n=5-6$, freeze-dried WIV with or without sugar; $n=6-8$, 
liquid WIV after 1 year at $20^{\circ} \mathrm{C} ; n=3$. Twenty-eight days after immunization, sera were collected for evaluation.

\section{ELISA}

ELISA assays were performed as described previously (41). Briefly, microtiter plates (Greiner, Alphen a/d Rijn, The Netherlands) coated with $0.2 \mu \mathrm{g}$ influenza H5N1 (NIBRG-14) subunit vaccine per well were blocked with a $2 \%$ milk solution. Two-fold serial dilutions of serum samples in $0.05 \%$ Tween 20/PBS (PBS/T) were added to the wells in duplicate and incubated for $1.5 \mathrm{~h}$. Bound H5N1-specific $\mathrm{IgG}$, $\mathrm{IgG} 1$ or $\mathrm{IgG} 2 \mathrm{a}$ antibodies were detected with a horseradish peroxidase-conjugated goat anti-mouse IgG-isotype antibody (Southern Biotech, Birmingham, AL). All incubations were performed at $37^{\circ} \mathrm{C}$. The staining was performed with $o$ phenylene-diamine (OPD) (Eastman Kodak Company) and absorbance at $492 \mathrm{~nm}$ was measured by an ELISA reader (Bio-tek Instruments, Inc.). The antibody titer was calculated by extrapolating the serum dilution corresponding to an OD of 0.2 using linear regression.

\section{Hemagglutination Inhibition Assay}

The hemagglutination inhibition (HI) assay was performed as described previously (42). In short, $50 \mu \mathrm{l}$ kaolin absorbed, heat-inactivated mouse serum in PBS (1:4) was serially diluted twofold in a microtiter plate in duplicate. Next, $50 \mu \mathrm{l}$ of four hemagglutination units (HAU) of H5N1 (NIBRG-14) virus in PBS was added and incubated for $40 \mathrm{~min}$ at RT. Finally, $50 \mu \mathrm{l}$ of $1 \%$ guinea pig erythrocytes (Harlan) in PBS was added to each well and HI titers were determined after $2 \mathrm{~h}$ incubation at RT. HI titers are given as the reciprocal of the highest serum dilution producing complete inhibition of hemagglutination.

\section{Statistical Analysis}

Statistical analysis on antibody titers was performed using the unpaired Student's $t$ test. $p$ values of $p<0.05$ and $p<0.01$ were considered statistically significant and highly significant, respectively.

\section{RESULTS}

Effect of Freeze-drying and Reconstitution on Vaccine Immunogenicity

WIV vaccines were freeze-dried with or without sugar and samples were stored, with WIV vaccine kept in suspension (liquid WIV). Immediately after drying, samples of each vaccine were reconstituted in water and tested alongside liquid WIV, to assess the effect of the actual freeze-drying process on the vaccines, and to obtain reference values for the storage experiments. Evaluation involved assessment of the hemagglutination or hemolytic activities of the vaccines as a measure for the structure and function of the viral particles. Any effect of inulin or trehalose on the hemagglutination and hemolysis assay was excluded, by testing a similar concentration of the freeze-dried sugar without viral particles. The results shown in Table I demonstrate that freeze-drying of
Table I. Effect of High Storage Temperature on Hemagglutination and Hemolysis Activity of the Vaccines

\begin{tabular}{lllll}
\hline \multicolumn{1}{c}{ Vaccine } & \multicolumn{2}{l}{ Hemagglutination titer } \\
$(10 \times 2 \mathrm{log})$ & & Hemolysis $(\%$ of max $)$ \\
\hline Temperature & - & $40^{\circ} \mathrm{C}$ & - & $40^{\circ} \mathrm{C}$ \\
Duration & 0 Day & 3 Months & 0 Day & 3 Months \\
Liquid & 11 & 5 & 67.9 & 0 \\
FD & $\geq 12$ & 7 & 90.6 & 4.3 \\
FDT & 11 & 8 & 81.5 & 35.3 \\
FDI & 11 & 8 & 83.3 & 15.1 \\
\hline
\end{tabular}

Immunization groups: liquid liquid WIV, $F D$ freeze-dried WIV without sugar, FDT freeze-dried WIV with trehalose, FDI freeze-dried WIV with inulin

WIV with or without trehalose or inulin did not have adverse effects on its hemagglutination or hemolytic activities. Preservation of these activities indicates that the sialic-acidbinding capacity and the membrane fusion activity of the HA proteins were retained.

To determine whether the preservation of in vitro vaccine activity after freeze-drying was accompanied by preservation of in vivo vaccine potency, mice were intramuscularly injected with vaccine doses of $5 \mu \mathrm{g}$ HA. Four weeks after immunization, the antibody responses induced by the freeze-dried vaccines were compared to those induced by liquid WIV. WIV freeze-dried without sugar (FD) induced slightly lower IgG titers $(p=0.001)$ than liquid WIV, while HI titers were not significantly diminished $(p=0.08$; Fig. 1a, b; 0 day). WIV freeze-dried with trehalose (FDT) was equally immunogenic as liquid WIV, while WIV freeze-dried with inulin (FDI) induced slightly lower IgG titers $(p=0.02)$ but similar HI titers. In conclusion, freeze-drying with or without sugar did not affect the immunogenic potency of H5N1 WIV vaccine substantially.

\section{Effect of Storage at Ambient Temperature on Vaccine Immunogenicity}

The freeze-dried vaccines and liquid WIV were subsequently stored at $20^{\circ} \mathrm{C}$. Three months and 1 year later, samples were tested for their capacity to induce antibody responses in mice. After 3 months of storage, no significant differences in serum IgG and HI titers induced by liquid WIV, FDT, or FDI vaccines were observed compared to liquid WIV conventionally stored at $4^{\circ} \mathrm{C}$ (Fig. 1a, b; 3 months). In contrast, FD vaccine induced substantially lower mean IgG and HI titers compared to liquid WIV at $4{ }^{\circ} \mathrm{C}(22.4$-fold $(p=0.03)$ and 3.5-fold $(p=0.04)$, respectively (Fig. 1a, b; 3 months). Consequently, FD vaccine was excluded from further evaluation.

After 1 year of storage at $20^{\circ} \mathrm{C}$, liquid WIV and both FDT and FDI still induced considerable H5N1-specific antibody responses. The mean $\mathrm{IgG}$ titer induced by liquid WIV stored at $20^{\circ} \mathrm{C}$ was only slightly, but not significantly $(p=0.07)$, lower than that induced by liquid WIV stored at $4^{\circ} \mathrm{C}$ (Fig. 1a, b; 1 year), and also the mean $\mathrm{HI}$ titer was not significantly altered (Fig. 1a, b; 1 year). IgG titers induced by FDI were moderately lower (2.2-fold, $p=0.005$ ) with only a marginal decrease in HI titers. FDT showed a more substantial decrease in both mean IgG and HI titers ( $p=0.003$ and $p=0.03$, respectively). 

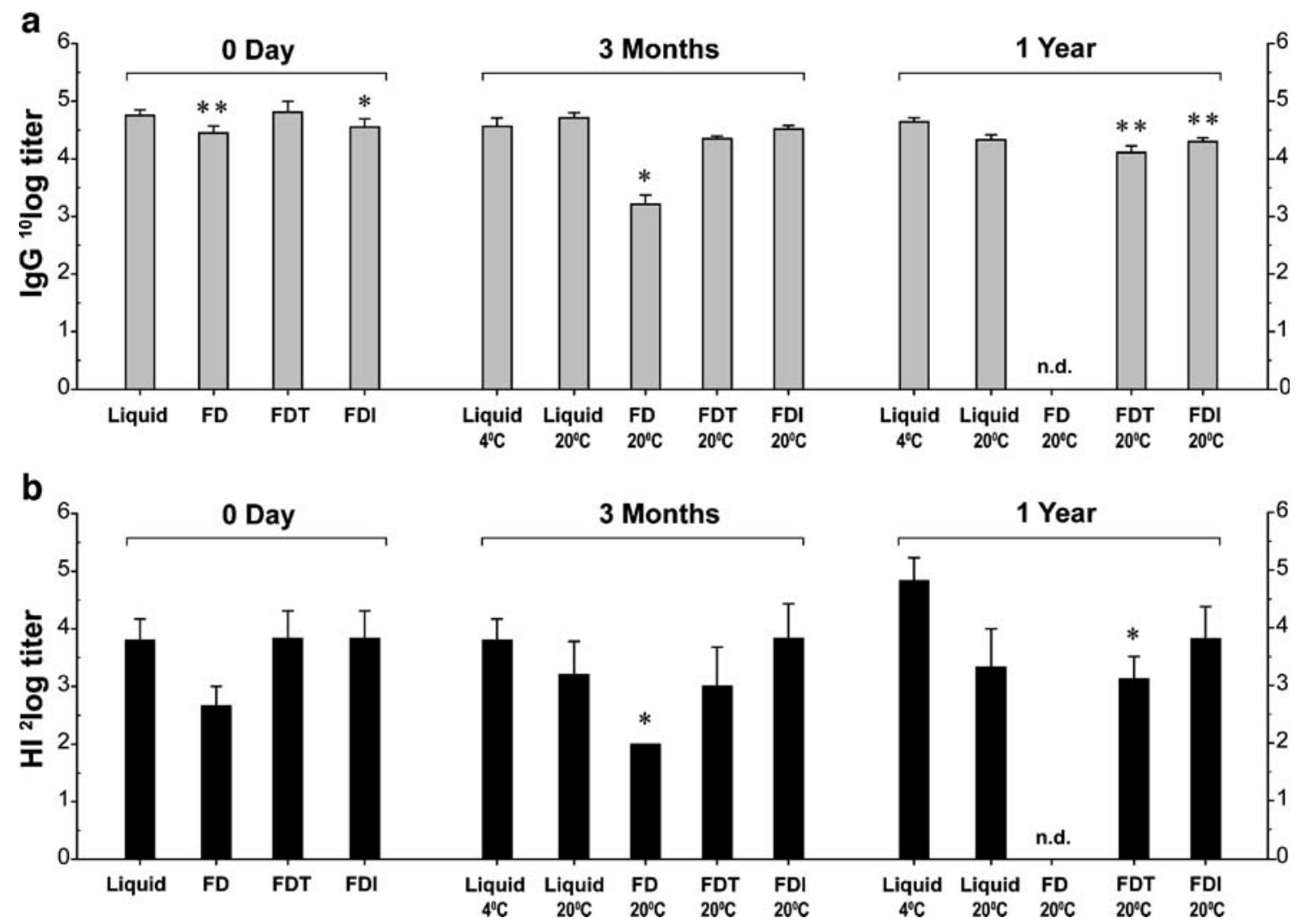

Fig. 1. Antibody responses induced by liquid and freeze-dried WIV vaccines before and after storage at ambient temperature. Serum H5N1-specific IgG titers were determined by ELISA and are given as geometric mean titers+standard error of the means (SEM), before storage, and after 3 months and 1 year storage (a). The serum capacity to inhibit agglutination of guinea pig erythrocytes by H5N1 vaccine virus is given in geometric mean HI titers+SEM, before storage, and after 3 months and 1 year of storage (b). Immunization groups are plotted on the $x$ axis with the vaccines' actual storage temperature in degrees Celsius: liquid liquid WIV, $F D$ freeze-dried WIV without sugar, $F D T$ freeze-dried WIV with trehalose, FDI freeze-dried WIV with inulin. HI titers below the detection limit were assigned half the value of the lowest detectable serum dilution, which was $8 . * p<0.05$, * $*<00.01$. nd not determined

Because ELISA and HI results obtained at different time points may be subject to inter-assay variation, (pooled) sera from all immunization experiments were tested in a single assay, in order to compare the immunogenicity of the vaccines over time (Fig. 2). Clearly, at $20^{\circ} \mathrm{C}$, the effect of storage duration on the immunogenic potency of the vaccine was minimal for liquid WIV and FDT and FDI vaccine. IgG titers dropped maximally by a factor of 1.9 (liquid WIV), and the maximum effect on HI titers was a twofold reduction (FDT and FDI), after 1 year of storage (Fig. 2a/b). More than twofold reductions in IgG or HI titers were only seen for FD vaccine after 3 months storage. In conclusion, liquid WIV and sugar-stabilized freeze-dried WIV revealed only minor reductions in the immunogenicity after 1 year of storage at $20^{\circ} \mathrm{C}$. At this condition, substantial deterioration of immunogenicity of WIV vaccine was seen only for WIV freeze-dried in absence of sugar excipient.

\section{Effect of High Storage Temperature on Vaccine Immunogenicity}

To simulate more challenging conditions vaccines may encounter during storage and transportation, the vaccines were put on shelf at $40^{\circ} \mathrm{C}$ for 3 months. These conditions negatively affected the hemagglutination and hemolysis activity of all vaccines, but strongest for liquid WIV and FD vaccine (Table I). Subsequent immunization of mice revealed a strong decrease in $\mathrm{IgG}$ and HI titers induced by liquid WIV stored at $40^{\circ} \mathrm{C}$, compared to WIV freshly prepared from a frozen virus stock (Fig. 3a, b). The immunogenic potency of vaccines freeze-dried with sugars was much better preserved under these challenging conditions. For FDT, vaccine a slight decrease in mean IgG titer (1.4-fold, $p=0.08)$ together with a more substantial decrease in HI titer (2.3-fold, $p=0.01$ ) was found. Responses to FDI vaccine were not significantly different from those to freshly prepared vaccine (Fig. 3a, b). In contrast, freeze-drying without additional measures to stabilize the vaccine resulted in strongly reduced $\mathrm{IgG}$ and $\mathrm{HI}$ titers after storage at $40^{\circ} \mathrm{C}$. Compared to liquid WIV stored at $40^{\circ} \mathrm{C}$, both FDT and FDI stored at $40^{\circ} \mathrm{C}$ induced significantly higher IgG titers ( $p=0.002$ and $p=0.00001$, respectively), and HI titers ( $p=0.002$ and $p=0.02$, respectively), which was not the case for FD vaccine (Fig. 3a, b).

The effect of high storage temperature relative to ambient storage temperature on vaccine immunogenicity is summarized in Fig. 4. Serum pools of the different immunization groups were run in a single assay, and the IgG and $\mathrm{HI}$ titers were plotted including those induced by liquid WIV stored at $4^{\circ} \mathrm{C}$ as a reference. The deteriorating effect of 
a
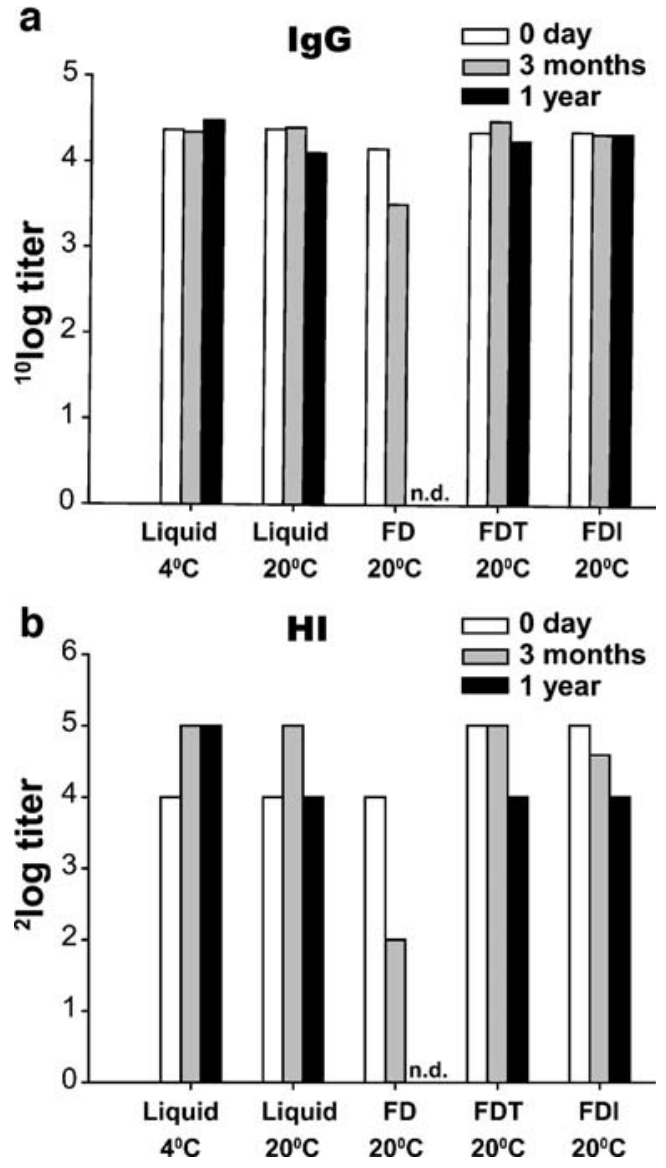

Fig. 2. Effect of storage duration on the vaccines capacity to induce antibody responses. Pooled sera of each group of mice immunized at different time points with liquid or freeze-dried WIV vaccine were tested simultaneously on H5N1-specific IgG or hemagglutinationinhibiting capacity. Bars represent the average values of duplicate determinations (deviations were less than 0.2). Immunization groups are plotted and labeled as in Fig. 1. Storage duration: 0 day (white bars), 3 months (gray bars), 1 year (black bars). $n d$ not determined

increasing temperature was most explicit for liquid WIV and FD vaccine. In case of FD formulation, maximum deterioration was already observed at moderate temperatures. If stored as FDT or FDI formulation, however, vaccines remained stable independent of the storage temperature.

\section{Preservation of the Quality of the Immune Response to WIV}

The ratio of $\operatorname{IgG} 2 \mathrm{a}$ and $\operatorname{IgG} 1$ subtype antibodies induced by the vaccine is important for protective efficacy. Relatively high IgG2a titers are representative of the Th1-type response characteristically induced by whole virus particles $(42,43)$ and are associated with better protection against a challenge with homologous virus in mice (44). We, therefore, evaluated the effect of freeze-drying and storage of the vaccine on the phenotype of the induced antibody response. When WIV was stored in buffer solution, the IgG2a-dominated antibody response was preserved at all storage temperatures and storage durations tested (Table II). Freeze-drying in absence of a stabilizing sugar excipient reduced the $\operatorname{IgG} 2 \mathrm{a} / \mathrm{IgG} 1$ ratio to the level of a mixed IgG2a/IgG1 phenotype. Subsequent storage of the FD vaccine further lowered the $\operatorname{IgG} 2 \mathrm{a} / \mathrm{IgG} 1$ ratio resulting in a shift to a IgG1-dominated antibody response within 3 months, independent of the storage temperature. In contrast, FDT and FDI vaccine induced an $\mathrm{IgG} 2 \mathrm{a}$-dominated antibody response after storage independent of storage duration and temperature.

\section{DISCUSSION}

The immunogenicity of WIV vaccine depends on the presence and integrity of the HA proteins and an intact viral particle structure $(42,45)$. The HA antigens provide the B-cell epitopes and define the specificity of the antibody response, while the viral particle acts as a vehicle for the vaccines primary immunopotentiating agent, the viral single-stranded RNA (ssRNA). Its immunopotentiating activity is exerted through binding to Toll-like receptor 7 (TLR7) in the endosomes of recipient host cells, and triggering of the innate immune system $(41,46,47)$. To a large extent, this mechanism accounts for the superior immunogenicity of WIV compared to split-virus formulations or subunit vaccines, which do not contain intact viral RNA (41). TLR7 signaling also determines the response type, being characteristically of a Th1
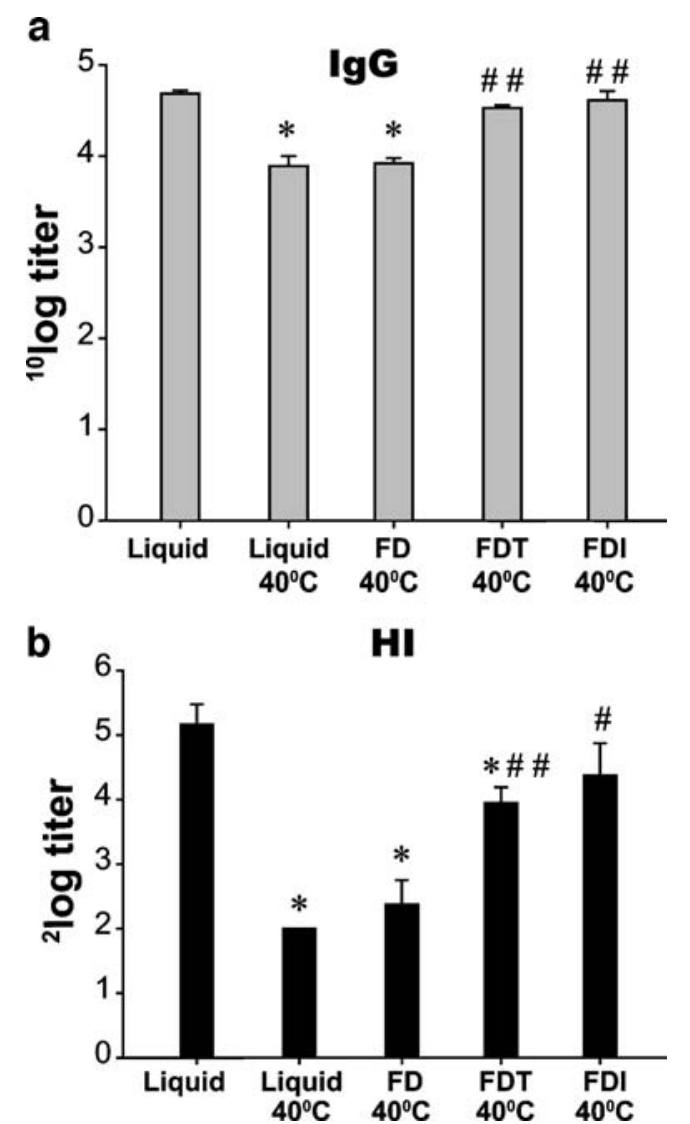

Fig. 3. Effect of high storage temperature on the immunogenic potency of the vaccines. Vaccines were stored for 3 months at $40^{\circ} \mathrm{C}$ and subsequently injected in mice. Serum H5N1-specific IgG titers (a) and HI titers (b) were determined, and are shown as geometric mean titers+SEM. Immunization groups are labeled as in Fig. 1. The group immunized with liquid WIV, which had not been subjected to the storage experiment, serves as a standard. $* p<0.05$ when compared with the standard; ${ }^{\#} p<0.05^{\# \#} p<0.01$ when compared with liquid WIV stored at $40^{\circ} \mathrm{C}$ 

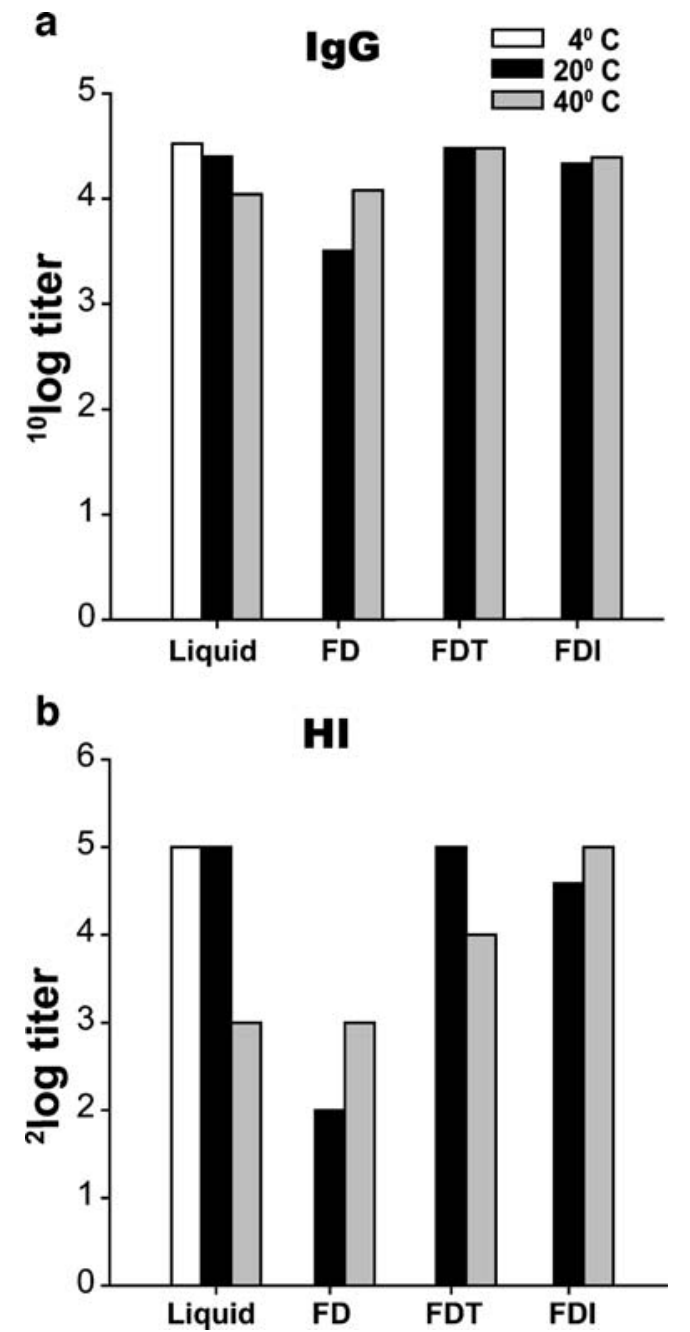

Fig. 4. Effect of storage temperature on the vaccines' capacity to induce antibody responses. Pooled sera of each group of mice immunized with liquid or freeze-dried WIV vaccine, which had been stored for 3 months at different temperatures, were tested simultaneously on H5N1-specific IgG or HI capacity. Bars represent the average values of duplicate determinations (deviations were less than 0.2). Immunization groups as in Fig. 1. Storage temperatures: $4^{\circ} \mathrm{C}$ (white bars), $20^{\circ} \mathrm{C}$ (gray bars), $40^{\circ} \mathrm{C}$ (black bars)

type for WIV, with a high amount of $\operatorname{IgG} 2 \mathrm{a} / \mathrm{c}$ antibodies in mice.

In liquid WIV vaccine, the antigenic properties of HA and the immunopotentiating activity provided by the ssRNA appear to be remarkably stable. Our results show that the immunogenicity of WIV vaccine stored in buffer solution at $20^{\circ} \mathrm{C}$ remained well preserved with minimal loss of activity over a period of at least 12 months. In contrast, seasonal subunit vaccine $(\mathrm{H} 3 \mathrm{~N} 2)$ stored in buffer solution at ambient $\left(25^{\circ} \mathrm{C}\right)$ temperature was reported to lose potency already over a period of 12 to 20 weeks (28). Compared to subunit vaccine, WIV, therefore, appears to be more stable. Yet, it should be noted that the comparability of the two studies is limited since they differ in the virus strains used for vaccine production and the method by which vaccine stability was assessed (in vivo immunogenicity versus SRID (31)). At high storage temperature $\left(40^{\circ} \mathrm{C}\right)$, the immunogenic potency of liquid WIV rapidly deteriorated. Progressive degradation of
HA antigens and/or loss of intact viral particles, as reflected in the strongly reduced hemagglutination and hemolytic activity of the vaccine, may likely be the cause. Yet, the antibody response remained Th1 skewed, which may indicate that a small amount of viral particles escaped degradation, as it was shown previously that even a very low dose of viral particles is sufficient for Th1 skewing of the response to WIV vaccine (44).

At high storage temperature, dry-powder formulations were superior to liquid WIV, as reported by others $(29,48)$. With the use of sugar stabilization no substantial loss of immunogenicity was observed after storage of freeze-dried WIV for 3 months at $40^{\circ} \mathrm{C}$. Furthermore, sugar stabilization played a critical role in preserving the Th1-skewing capacity of the vaccine during freezedrying and subsequent storage. Freeze-drying in absence of sugar led to a mixed Th1/Th2 antibody response, which further shifted during storage at elevated temperature to an overt Th2 type response, while the characteristic Th1 phenotype of the WIV response was retained when sugars were used during freezedrying. Sugar molecules obviously play a role in preserving effective TLR7 signaling by the ssRNA, probably by stabilizing the viral particle structure and protecting the viral ssRNA from degradation. Sugars are known to stabilize enveloped viruses during freeze-drying $(49,50)$, and trehalose and inulin have the capacity to stabilize lipid bilayers $(35,36,51)$. In freeze-drying experiments with 'empty' viral envelopes (virosomes), use of inulin was found to preserve the vesicular structure, while absence of sugar stabilization resulted in complete disintegration after rehydration (38). The mode of action of trehalose and inulin is presumably by replacement of the water molecules situated in between the hydrophilic heads of the lipids. Hereby, a detrimental phase transition of the viral membrane upon rehydration is prevented and the vaccine particles are preserved (35).

By assessing immunogenicity in vivo we discovered an important role for sugar compounds in preserving not only the quantity but also the quality of the immune response to WIV after freeze-drying and storage. Previous storage studies that showed improved stability of freeze-dried WIV used the hemagglutination assay to determine vaccine stability, which provides a quantitative measure only $(29,33)$. The shift from a Th1 response to WIV before freeze-drying to a Th2 response to WIV after freeze-drying in absence of sugar-stabilization could not have been predicted from hemagglutination results,

Table II. Dominance of IgG Subtypes in the Antibody Response to Vaccination. Immunization Groups are Labeled as in Table I

\begin{tabular}{|c|c|c|c|c|}
\hline Vaccine & & 0 months & 3 months & 12 months \\
\hline \multirow[t]{3}{*}{ Liquid } & $4^{\circ} \mathrm{C}$ & $\lg \mathrm{G} 2 \mathrm{a}^{a}$ & $\lg G 2 a$ & $\lg G 2 a$ \\
\hline & $20^{\circ} \mathrm{C}$ & nd & $\lg G 2 a$ & $\lg G 2 a$ \\
\hline & $40^{\circ} \mathrm{C}$ & nd & $\lg G 2 a$ & nd \\
\hline \multirow[t]{2}{*}{ FD } & $20^{\circ} \mathrm{C}$ & $\lg \mathrm{G} 1 / \lg \mathrm{G} 2 \mathrm{a}^{b}$ & $\lg G 1$ & nd \\
\hline & $40^{\circ} \mathrm{C}$ & nd & $\lg \mathrm{G} 1$ & nd \\
\hline \multirow[t]{2}{*}{ FDT } & $20^{\circ} \mathrm{C}$ & $\lg G 2 a$ & $\lg G 2 a$ & $\lg \mathrm{G} 2 \mathrm{a}$ \\
\hline & $40^{\circ} \mathrm{C}$ & nd & $\lg G 2 a$ & nd \\
\hline \multirow[t]{2}{*}{ FDI } & $20^{\circ} \mathrm{C}$ & $\lg G 2 a$ & $\lg G 2 a$ & $\lg G 2 a$ \\
\hline & $40^{\circ} \mathrm{C}$ & nd & $\lg G 2 a$ & nd \\
\hline
\end{tabular}

nd not done

${ }^{a} \mathrm{IgG} 2 \mathrm{a}$ or $\mathrm{IgG} 1$ were defined dominant if the $\mathrm{IgG} 2 \mathrm{a} / \mathrm{IgG} 1$ ratio was $\geq 1.5$ or $\leq 0.5$, respectively

${ }^{b}$ For ratios between 0.5 and 1.5 , the response was defined as mixed 
nor by other in vitro tests that assess the integrity of the HA component, like the SRID. In vitro HA stability tests alone are therefore insufficient to obtain a complete representation of WIV vaccine stability.

The efficacy of influenza vaccines is determined by the induction of an effective antibody response. The serum HI titer, which is a measure for the magnitude of the antibody response, is the principle correlate of protection used to evaluate the efficacy of current human seasonal and prepandemic influenza vaccines. For seasonal vaccines an $\mathrm{HI}$ titer of $>40$ is considered to be protective (52-55). For the mouse model, no protective titer has been defined. Due to the intrinsic low immunogenicity of $\mathrm{H} 5 \mathrm{~N} 1$ virus and the singledose immunization scheme the maximal titer reached in our experiments was 32. It has to be noted that immunogenicity in terms of $\mathrm{HI}$ and $\mathrm{IgG}$ titers does not necessarily correlate with protective efficacy. In the mouse model, the relative amounts of $\mathrm{IgG} 1$ and $\mathrm{IgG} 2 \mathrm{a}$ (or IgG2c), expressed in the $\mathrm{IgG} 2 \mathrm{a} / \mathrm{IgG} 1$ ratio, appear to be decisive for protection $(40,56,57)$. IgG2adominated responses are clearly more effective than $\mathrm{IgG1}$ dominated responses. Yet, in the absence of significant differences in $\mathrm{HI}$ and $\mathrm{IgG}$ titers and similar $\mathrm{IgG}$ subtype dominance, as observed, for example, for liquid WIV, FDI, and FDT during storage at ambient temperatures, protective efficacy is likely to be comparable.

The preservability of WIV vaccine is strongly increased by sugar stabilization and freeze-drying. Similarly, other formulations like subunit, split-virus, and virosome (31) vaccines have been successfully freeze-dried and stabilized with sugars (summarized in (31)). Yet, a combination of increased stability together with specific features of WIV which promote vaccine availability, like strong immunogenicity, dose sparing quality and manufacturing simplicity (46), make dry-powder WIV an apt candidate formulation for prepandemic stockpiling. Based on the results of storage at $40^{\circ} \mathrm{C}$ it may also be predicted that dry-powder WIV will have a shelf-life exceeding that of liquid WIV, when kept under optimal refrigerated conditions $(52,58)$. An extended vaccine shelf-life could delay costly replacement of stocks when vaccines reach their expiry date. In case of a pandemic emergency, deployment of dry-powder vaccine stocks may be exerted without refrigeration unless the temperatures are extremely high. This could speed up pandemic intervention and reduce losses due to cold-chain failures.

\section{CONCLUSION}

The lack of suitable vaccines during the initial emergence of the New Influenza A (H1N1)swl pandemic virus in 2009, and its rapidly global spread underscores the importance of effective pre-pandemic vaccine stockpiles. Although this virus was of an unforeseen subtype, it remains important that stockpiles of vaccines against identified potentially dangerous virus strains like the H5N1 virus are prepared and kept in place. Our results suggest that for stockpiling liquid H5N1 WIV vaccine refrigeration may not be an absolute requirement to preserve the vaccines immunogenicity, as long as the temperature remains below $20^{\circ} \mathrm{C}$. Furthermore, conversion from liquid to dry-powder formulation increases the versatility of WIV vaccine by allowing storage outside the fridge at higher temperatures, up to $40^{\circ} \mathrm{C}$ for at least 3 months. Because of its improved stability, use of sugar- stabilized freeze-dried H5N1 WIV vaccine could increase the efficacy of pre-pandemic stockpiling and subsequent vaccine deployment.

\section{ACKNOWLEDGMENTS}

We thank the NIBSC for providing NIBRG-14 influenza virus. We thank Tjalke Westra and Tjarko Meijerhof for technical assistance. This study was conducted under the auspices of the Netherlands Influenza Vaccine Research Center (NIVAREC), with financial support from the Netherlands Organization for Health Research and Development (ZonMw).

Open Access This article is distributed under the terms of the Creative Commons Attribution Noncommercial License which permits any noncommercial use, distribution, and reproduction in any medium, provided the original author(s) and source are credited.

\section{REFERENCES}

1. Johnson NP, Mueller J. Updating the accounts: global mortality of the 1918-1920 "Spanish" influenza pandemic. Bull Hist Med. 2002;76:105-15.

2. World Health Organization http://www.who.int/mediacentre/ news/statements/2009/h1n1_pandemic_phase6_20090611/en/ index.html.

3. Dawood FS, Jain S, Finelli L, Shaw MW, Lindstrom S, Garten $\mathrm{RJ}$, et al. Emergence of a novel swine-origin influenza A (H1N1) virus in humans. N Engl J Med. 2009;360:2605-15.

4. Update: novel influenza A (H1N1) virus infections-worldwide, May 6, 2009. MMWR Morb Mortal Wkly Rep. 2009;58:453-8.

5. Fraser C, Donnelly CA, Cauchemez S, Hanage WP, Van Kerkhove MD, Hollingsworth TD, et al. Pandemic potential of a strain of influenza A (H1N1): early findings. Science. 2009;324:1557-61.

6. World Health Organization http://www.who.int/csr/don/ 2009_06_12/en/index.html.

7. Nguyen-Van-Tam JS, Hampson AW. The epidemiology and clinical impact of pandemic influenza. Vaccine. 2003;21:1762-8.

8. Fedson DS. Vaccine development for an imminent pandemic: why we should worry, what we must do. Hum Vaccin. 2006;2:38-42.

9. Taubenberger JK, Reid AH, Lourens RM, Wang R, Jin G, Fanning TG. Characterization of the 1918 influenza virus polymerase genes. Nature. 2005;437:889-93.

10. World Health Organization http://www.who.int/csr/disease/avian_ influenza/country/cases_table_2009_06_02/en/index.html.

11. World Health Organization http://www.who.int/csr/resources/ publications/influenza/WHO_CDS_CSR_GIP_2005_5/en/.

12. Uscher-Pines L, Omer SB, Barnett DJ, Burke TA, Balicer RD. Priority setting for pandemic influenza: an analysis of national preparedness plans. PLoS Med. 2006;3:e436.

13. Monto AS. Vaccines and antiviral drugs in pandemic preparedness. Emerg Infect Dis. 2006;12:55-60.

14. Hayden FG, Pavia AT. Antiviral management of seasonal and pandemic influenza. J Infect Dis. 2006;194 Suppl 2:S119-26.

15. Longini Jr IM, Nizam A, Xu S, Ungchusak K, Hanshaoworakul $\mathrm{W}$, Cummings DA, et al. Containing pandemic influenza at the source. Science. 2005;309:1083-7.

16. Ehrlich HJ, Muller M, Oh HM, Tambyah PA, Joukhadar C, Montomoli E, et al. A clinical trial of a whole-virus $\mathrm{H} 5 \mathrm{~N} 1$ vaccine derived from cell culture. N Engl J Med. 2008;358:2573-84.

17. Leroux-Roels I, Borkowski A, Vanwolleghem T, Drame M, Clement F, Hons E, et al. Antigen sparing and cross-reactive immunity with an adjuvanted $\mathrm{rH} 5 \mathrm{~N} 1$ prototype pandemic influenza vaccine: a randomised controlled trial. Lancet. 2007;370:580-9. 
18. Levie K, Leroux-Roels I, Hoppenbrouwers K, Kervyn AD, Vandermeulen C, Forgus S, et al. An adjuvanted, low-dose, pandemic influenza A (H5N1) vaccine candidate is safe, immunogenic, and induces cross-reactive immune responses in healthy adults. J Infect Dis. 2008;198:642-9.

19. Lin J, Zhang J, Dong X, Fang H, Chen J, Su N, et al. Safety and immunogenicity of an inactivated adjuvanted whole-virion influenza A (H5N1) vaccine: a phase I randomised controlled trial. Lancet. 2006;368:991-7.

20. Baras B, Stittelaar KJ, Simon JH, Thoolen RJ, Mossman SP, Pistoor FH, et al. Cross-protection against lethal H5N1 challenge in ferrets with an adjuvanted pandemic influenza vaccine. PLoS One. 2008;3:e1401.

21. Fazekas G, Martosne-Mendi R, Jankovics I, Szilvasy I, Vajo Z. Cross-reactive immunity to clade 2 strains of influenza virus A subtype H5N1 induced in adults and elderly patients by Fluval, a prototype pandemic influenza virus vaccine derived by reverse genetics, formulated with a phosphate adjuvant, and directed to clade 1 strains. Clin Vaccine Immunol. 2009;16:437-43.

22. Govorkova EA, Webby RJ, Humberd J, Seiler JP, Webster RG. Immunization with reverse-genetics-produced H5N1 influenza vaccine protects ferrets against homologous and heterologous challenge. J Infect Dis. 2006;194:159-67.

23. Murakami S, Iwasa A, Iwatsuki-Horimoto K, Ito M, Kiso M, Kida $\mathrm{H}$, et al. Cross-clade protective immunity of H5N1 influenza vaccines in a mouse model. Vaccine. 2008;26:6398-404.

24. Ferguson NM, Cummings DA, Cauchemez S, Fraser C, Riley S, Meeyai A, et al. Strategies for containing an emerging influenza pandemic in Southeast Asia. Nature. 2005;437:209-14.

25. Riley S, Wu JT, Leung GM. Optimizing the dose of prepandemic influenza vaccines to reduce the infection attack rate. PLoS Med. 2007;4:e218.

26. Goji NA, Nolan C, Hill H, Wolff M, Noah DL, Williams TB, et al. Immune responses of healthy subjects to a single dose of intramuscular inactivated influenza A/Vietnam/1203/2004 (H5N1) vaccine after priming with an antigenic variant. J Infect Dis. 2008; 198:635-41.

27. Jennings LC, Monto AS, Chan PK, Szucs TD, Nicholson KG. Stockpiling prepandemic influenza vaccines: a new cornerstone of pandemic preparedness plans. Lancet Infect Dis. 2008;8:650-8.

28. Coenen F, Tolboom JT, Frijlink HW. Stability of influenza subunit vaccine. Does a couple of days outside the refrigerator matter? Vaccine. 2006;24:525-31.

29. Huang J, Garmise RJ, Crowder TM, Mar K, Hwang CR, Hickey AJ, et al. A novel dry powder influenza vaccine and intranasal delivery technology: induction of systemic and mucosal immune responses in rats. Vaccine. 2004;23:794-801.

30. Schoub BD, Cameron NA. Problems encountered in the delivery and storage of OPV in an African country. Dev Biol Stand. 1996;87:27-32.

31. Amorij JP, Huckriede A, Wilschut J, Frijlink HW, Hinrichs WL. Development of stable influenza vaccine powder formulations: challenges and possibilities. Pharm Res. 2008;25:1256-73.

32. Wang W. Lyophilization and development of solid protein pharmaceuticals. Int J Pharm. 2000;203:1-60.

33. Amorij JP, Meulenaar J, Hinrichs WL, Stegmann T, Huckriede $\mathrm{A}$, Coenen $\mathrm{F}$, et al. Rational design of an influenza subunit vaccine powder with sugar glass technology: preventing conformational changes of haemagglutinin during freezing and freeze-drying. Vaccine. 2007;25:6447-57.

34. Maa YF, Ameri M, Shu C, Payne LG, Chen D. Influenza vaccine powder formulation development: spray-freeze-drying and stability evaluation. J Pharm Sci. 2004;93:1912-23.

35. Crowe LM, Crowe JH, Rudolph A, Womersley C, Appel L. Preservation of freeze-dried liposomes by trehalose. Arch Biochem Biophys. 1985;242:240-7.

36. Vereyken IJ, Chupin V, Hoekstra FA, Smeekens SC, de Kruijff B. The effect of fructan on membrane lipid organization and dynamics in the dry state. Biophys J. 2003;84:3759-66.

37. Williams MS, Mayner RE, Daniel NJ, Phelan MA, Rastogi SC, Bozeman FM, et al. New developments in the measurement of the hemagglutinin content of influenza virus vaccines by singleradial-immunodiffusion. J Biol Stand. 1980;8:289-96.
38. de Jonge J, Amorij JP, Hinrichs WL, Wilschut J, Huckriede A, Frijlink HW. Inulin sugar glasses preserve the structural integrity and biological activity of influenza virosomes during freeze-drying and storage. Eur J Pharm Sci. 2007;32:33-44.

39. Hinrichs WL, Prinsen MG, Frijlink HW. Inulin glasses for the stabilization of therapeutic proteins. Int J Pharm. 2001;215:163-74.

40. Stegmann T, Morselt HW, Booy FP, van Breemen JF, Scherphof G, Wilschut J. Functional reconstitution of influenza virus envelopes. EMBO J. 1987;6:2651-9.

41. Geeraedts F, Goutagny N, Hornung V, Severa M, de Haan A, Pool J, et al. Superior immunogenicity of inactivated whole virus $\mathrm{H} 5 \mathrm{~N} 1$ influenza vaccine is primarily controlled by Toll-like receptor signalling. PLoS Pathog. 2008;4:e1000138.

42. Geeraedts F, Bungener L, Pool J, ter Veer W, Wilschut J, Huckriede A. Whole inactivated virus influenza vaccine is superior to subunit vaccine in inducing immune responses and secretion of proinflammatory cytokines by DCs. Influenza Other Respi Viruses. 2008;2:41-51.

43. Hovden AO, Cox RJ, Haaheim LR. Whole influenza virus vaccine is more immunogenic than split influenza virus vaccine and induces primarily an $\mathrm{IgG} 2 \mathrm{a}$ response in $\mathrm{BALB} / \mathrm{c}$ mice. Scand J Immunol. 2005;62:36-44.

44. Bungener L, Geeraedts F, Ter Veer W, Medema J, Wilschut J, Huckriede A. Alum boosts TH2-type antibody responses to whole-inactivated virus influenza vaccine in mice but does not confer superior protection. Vaccine. 2008;26:2350-9.

45. Hagenaars N, Mastrobattista E, Glansbeek H, Heldens J, van den Bosch H, Schijns V, et al. Head-to-head comparison of four nonadjuvanted inactivated cell culture-derived influenza vaccines: effect of composition, spatial organization and immunization route on the immunogenicity in a murine challenge model. Vaccine. 2008;26:6555-63.

46. World Health Organization http://www.who.int/vaccines-docu ments/DocsPDF06/863.pdf.

47. Diebold SS, Kaisho T, Hemmi H, Akira S, Reis e Sousa C. Innate antiviral responses by means of TLR7-mediated recognition of single-stranded RNA. Science. 2004;303:1529-31.

48. Garmise RJ, Staats HF, Hickey AJ. Novel dry powder preparations of whole inactivated influenza virus for nasal vaccination. AAPS PharmSciTech. 2007;8:E81.

49. Levy JA, Fieldsteel AH. Freeze-drying is an effective method for preserving infectious type $\mathrm{C}$ retroviruses. J Virol Methods. 1982;5:165-71.

50. Yannarell DA, Goldberg KM, Hjorth RN. Stabilizing coldadapted influenza virus vaccine under various storage conditions. J Virol Methods. 2002;102:15-25.

51. Hincha DK, Zuther E, Hellwege EM, Heyer AG. Specific effects of fructo- and gluco-oligosaccharides in the preservation of liposomes during drying. Glycobiology. 2002;12:103-10.

52. ICH Harmonised Tripartite Guideline http://www.ich.org/LOB/ media/MEDIA419.pdf

53. Koyama S, Ishii KJ, Kumar H, Tanimoto T, Coban C, Uematsu $\mathrm{S}$, et al. Differential role of TLR- and RLR-signaling in the immune responses to influenza A virus infection and vaccination. J Immunol. 2007;179:4711-20.

54. Hobson D, Curry RL, Beare AS, Ward-Gardner A. The role of serum haemagglutination-inhibiting antibody in protection against challenge infection with influenza $\mathrm{A} 2$ and $\mathrm{B}$ viruses. J Hyg (Lond). 1972;70:767-77.

55. P.M. Kendal AP, Skehel J. Concepts and procedures for laboratory-based influenza surveillance. Centers for Disease Control, Atlanta, GA. Publication No. B17-35. (1982).

56. Hovden AO, Cox RJ, Madhun A, Haaheim LR. Two doses of parenterally administered split influenza virus vaccine elicited high serum IgG concentrations which effectively limited viral shedding upon challenge in mice. Scand J Immunol. 2005;62:342-52.

57. Huber VC, McKeon RM, Brackin MN, Miller LA, Keating R, Brown SA, et al. Distinct contributions of vaccine-induced immunoglobulin G1 (IgG1) and IgG2a antibodies to protective immunity against influenza. Clin Vaccine Immunol. 2006;13:981-90.

58. Krause PR. Goals of stability evaluation throughout the vaccine life cycle. Biologicals. 2009;37:369-78. discussion 421-3. 